\title{
Systematic Review of Interventions to Increase Stool Blood Colorectal Cancer Screening in African Americans
}

\author{
Siddhartha Roy ${ }^{1,2} \cdot$ Sabrina Dickey ${ }^{3} \cdot$ Hsiao-Lan Wang ${ }^{4} \cdot$ Alexandria Washington $^{5} \cdot$ Randy Polo $^{6} \cdot$ Clement K. Gwede $^{7}$. \\ John S. Luque ${ }^{5}$
}

Published online: 24 June 2020

(C) Springer Science+Business Media, LLC, part of Springer Nature 2020

\begin{abstract}
African Americans experience colorectal cancer (CRC) related disparities compared to other racial groups in the United States. African Americans are frequently diagnosed with CRC at a later stage, screening is underutilized, and mortality rates are highest in this group. This systematic review focused on intervention studies using stool blood CRC screening among African Americans in primary care and community settings. Given wide accessibility, low cost, and ease of dissemination of stool-based CRC screening tests, this review aims to determine effective interventions to improve participation rates. This systematic review included intervention studies published between January 1, 2000 and March 16, 2019. After reviewing an initial search of 650 studies, 11 studies were eventually included in this review. The included studies were studies conducted in community and clinical settings, using both inreach and outreach strategies to increase CRC screening. For each study, an unadjusted odds ratio (OR) for the CRC screening intervention compared to the control arm was calculated based on the data in each study to report effectiveness. The eleven studies together recruited a total of 3334 participants. The five studies using two-arm experimental designs ranged in effectiveness with ORs ranging from 1.1 to 13.0 using interventions such as mailed reminders, patient navigation, and tailored educational materials. Effective strategies to increase stool blood testing included mailed stool blood tests augmented by patient navigation, tailored educational materials, and follow-up calls or mailings to increase trust in the patient-provider relationship. More studies are needed on stool blood testing interventions to determine effectiveness in this population.
\end{abstract}

Keywords Colorectal cancer $\cdot$ Cancer screening $\cdot$ Stool blood tests $\cdot$ Colonoscopy $\cdot$ African Americans

John S. Luque

john.luque@famu.edu

1 Department of Family and Community Medicine, Pennsylvania State University Health Milton S. Hershey Medical Center, Hershey, PA, USA

2 Department of Cancer Control, Penn State Cancer Institute, Hershey, PA, USA

3 College of Nursing, Florida State University, Tallahassee, FL, USA

4 College of Nursing, University of South Florida, Tampa, FL, USA

5 College of Pharmacy and Pharmaceutical Sciences, Institute of Public Health, Florida A\&M University, 1415 South Martin Luther King, Jr. Blvd, Tallahassee, FL 32307, USA

6 University Libraries, University of South Florida, Tampa, FL, USA

7 Division of Population Sciences, Department of Health Outcomes and Behavior, Moffitt Cancer Center, Tampa, FL, USA

\section{Introduction}

Although all population groups in the U.S. are affected by cancer, minority communities experience a higher cancer burden. Notably, African Americans exhibit higher cancer death rates and lower survival rates compared to other racial or ethnic groups [1]. Minority communities are more likely to be poor, medically underserved, and have limited access to quality health care, leading to cancer health disparities. These persistent disparities may be attributed in part to lower rates of completing recommended cancer screenings and increased risk factors, which are more prevalent among low-income and uninsured individuals living in minority communities [1].

Colorectal cancer (CRC) is the third most commonly diagnosed cancer in men and women in the United States with an estimated 101,420 new cases [2]. CRC continues to affect African Americans at disproportionately higher rates 
than non-Hispanic whites despite improved screening and treatment (Jackson, Oman, Patel \& Vega, 2016). The CRC incidence rate between 2011 and 2015 was 24\% higher for African American men and 19\% higher for African American women [1]. Moreover, CRC mortality rates were $47 \%$ higher in African American men and 34\% higher in African American women than in non-Hispanic whites [1]. The cancer health disparity in mortality is decreasing at a faster rate in African American women than in men, possibly due to differences in risk factors (e.g., physical activity and diet) and from higher CRC screening rates in women which has improved early detection [1]. Other factors associated with CRC disparities across the cancer continuum may include genetic and microbiomic influences, differences in tumor biology, environmental causes, structural barriers such as costs, transportation and availability of healthcare facilities, and individual barriers including lack of knowledge, low self-efficacy, low health literacy, and mistrust of providers $[3,4]$. Patient factors, provider-related factors, health care system-related factors, and structural factors all contribute to CRC disparities for African Americans [4]. In the current era of COVID-19, elective surgeries are being postponed and cancer screenings deferred because of fear of exposure to the virus in hospitals and clinics; therefore, mail-based screenings such as stool blood CRC screening are a safer alternative.

\section{Colorectal Cancer Screening Recommendations}

The U.S. Preventive Service Task Force recommends that screening for CRC start at age 50 and continue until age 75 [5]. CRC screening options generally include a high-sensitivity stool blood test [fecal immunochemical test (FIT), guaiac-based fecal occult blood test (gFOBT), or multitarget stool FIT-DNA test)] or a direct visualization test (colonoscopy, flexible sigmoidoscopy, or CT colonography). Early detection with colonoscopy can detect precancerous polyps and abnormalities in the colon and rectum to reduce mortality with this test which is done every 10 years. CRC screening may also involve annual stool blood tests, such as the FIT or gFOBT, and follow-up with diagnostic colonoscopy if needed for abnormal findings. Communication of abnormal FIT results are associated with improved adherence to follow-up colonoscopy [6].

The American Cancer Society (ACS) recently updated its screening recommendations with a "qualified recommendation" for beginning CRC screening for adults beginning at 45 years old and a "strong recommendation" for beginning screening at 50 years and older until the age of 75 in May 2018. A recent study reported that CRC screening more than doubled among people between 45 and 49 years since the
ACS guideline change [7]. In 2009, the American College of Gastroenterology (ACG) recommended that African Americans begin screening at 45 years old [8,9]. The difference in age recommendations is related to the type and quality of evidence for individuals aged 45-49 years old. Currently, the most common tests used in the U.S. to adhere to CRC screening recommendations include either a colonoscopy every 10 years or an annual stool blood test (FIT or gFOBT).

There is no consensus on which test recommendation will yield higher adherence rates to CRC screening recommendations; however, studies suggest that stool blood tests may be more acceptable and beneficial for African American communities to reach recommended screening levels [10]. Moreover, there are many regions of the U.S. where access to colonoscopy is suboptimal [11]. A previous systematic review focused on CRC screening by colonoscopy in African Americans concluded that patient, provider, and systematic barriers to screening could be modifiable to improve screening rates [12]. These barriers were classified into the following three domains: (1) patient factors-psychological (fear) and lack of knowledge; (2) provider factors-confusion about age recommendations, low knowledge of patient barriers, and lack of counseling; and (3) system factorscosts, insurance coverage, and limited primary care visits [12]. Other barriers to CRC screening adherence include difficulty in scheduling appointments, provider preferences for one screening modality over another which may limit access, poor healthcare infrastructure including low access to gastroenterology specialists, and available health education resources. While many CRC screening interventions focus on increasing colonoscopy screening, stool blood tests can be done in the privacy of a person's home, are more cost effective, and can yield higher rates of adherence [13, 14].

While there are many different intervention possibilities to ameliorate these cancer health disparities, focusing on increasing colorectal cancer screening in minority and underserved communities is one that has been widely implemented in both health care system and communitybased contexts using both outreach and inreach strategies [15-21]. Many of these programs emphasize colonoscopy screening, which is an example of an invasive screening, but several other methods of noninvasive screening tests exist, but require more frequent screening intervals. Mailed invitations to complete stool blood testing is an effective outreach approach frequently used by medical providers.

To critically assess and synthesize the available evidence for the effectiveness of colorectal cancer screening programs in primary and community health care, this systematic review aims to review quality studies testing different strategies for increasing stool blood colorectal cancer screening rates in African Americans. There have been no systematic reviews focused specifically on clinical and behavioral interventions to increase stool blood colorectal screening. Studies 
might include both endoscopic and stool blood methods for their outcomes, but this review sought to identify studies focused on stool blood testing, as a less expensive alternative to colonoscopy in minority communities. The objective of this systematic review is to assess the effectiveness of colorectal cancer screening using stool blood testing approaches, specifically in studies which included either exclusively African Americans, or were conducted in health systems with a high proportion of African American patients.

\section{Methods}

\section{Search Criteria and Study Selection}

The inclusion criteria were the following items:

1. Studies using a randomized controlled trial or quasiexperimental study design. Control groups could include both usual care or other types of clinical or behavioral interventions to increase colorectal cancer screening such as may be used in comparative effectiveness study designs.

2. Studies had to include substantial participants of African Americans ( $>50 \%$ of the study sample) and be conducted in the U.S.

3. Studies needed to include a screening completion outcome involving stool blood testing such as high sensitivity and high specificity gFOBT, FOBT, or FIT.

4. Only peer-reviewed studies published in scientific journals were included.

The exclusion criteria were the following items:

1. Studies that were literature reviews, case studies, or quality improvement initiatives without an experimental research design.

2. Studies that did not include a comparison group.

3. Studies that duplicated the findings from another previously published study to report findings on a subset of participants from the original study.

4. Studies that did not measure a colorectal cancer screening outcome, such as studies which only measured changes in knowledge or screening intentions.

5. Studies that did not include greater than 50\% African Americans in the participant sample.

6. Studies conducted outside of the U.S.

A research librarian searched bibliographic databases which included Scopus, Web of Science, and CINAHL from database inception until March 16, 2019. The following syntax illustrates the search strategy used: ((colon OR colorectal OR sigmoid OR rectum OR rectal OR colonic OR anus) N5 (cancer OR neoplasm OR tumor OR tumour)) AND (((stool OR feces OR fecal OR faeces OR faecal) N5 ( screen* OR specimen)) OR immunochem* OR immunoassay* OR "occult blood" OR fobt) AND (black OR blacks OR "african american" OR "african americans")

After the search of bibliographic databases, 650 citations were identified. Eight references were eliminated since there were no author names and were either published guidelines or news articles that included no screening outcome or intervention. Next, 269 duplicates were identified, and the database was reduced to 381 references. Two independent reviewers examined the remaining articles using the inclusion and exclusion criteria and 25 articles met criteria for full text review. Articles published before 2000 were eliminated. The rationale for excluding older articles was to account for recent advances in stool blood CRC testing technology, such as the introduction of stool DNA (sDNA) technology in 2000 and the later approval of FIT by the Centers for Medicare and Medicaid Services (CMS) in 2003 [13]. A third reviewer examined all decisions of the two independent reviewers to resolve disagreements on article inclusion and conducted the full text review of the 25 articles (Fig. 1). After a thorough review of each article, 14 articles were additionally excluded, leaving a final group of 11 articles for article abstraction [14, 22-31]. The most common reasons for excluding articles included: (1) less than 50\% of the study sample were African American; (2) did not meet study design parameters; (3) no study outcomes included stool blood test outcomes; and (4) review articles or qualitative studies.

\section{Study Coding}

To abstract information from each study, the reviewers employed a form adapted from a previous systematic review [32]. The form included questions on sample setting, sample size, study design, randomization procedures, follow-up time periods, target population, intervention description, control group description, participant demographics, type of screening tests, means of screening confirmation (chart versus self-report), and study outcomes by study arm and screening adherence. Two reviewers collected information from the included articles independently on the article abstraction form and discussed any discrepancies in data abstraction to come to consensus.

\section{Analysis}

There was substantial heterogeneity among the studies identified based on study design, sample size, follow-up time period to measure outcomes, and study site/setting. For example, several studies used more conventional 


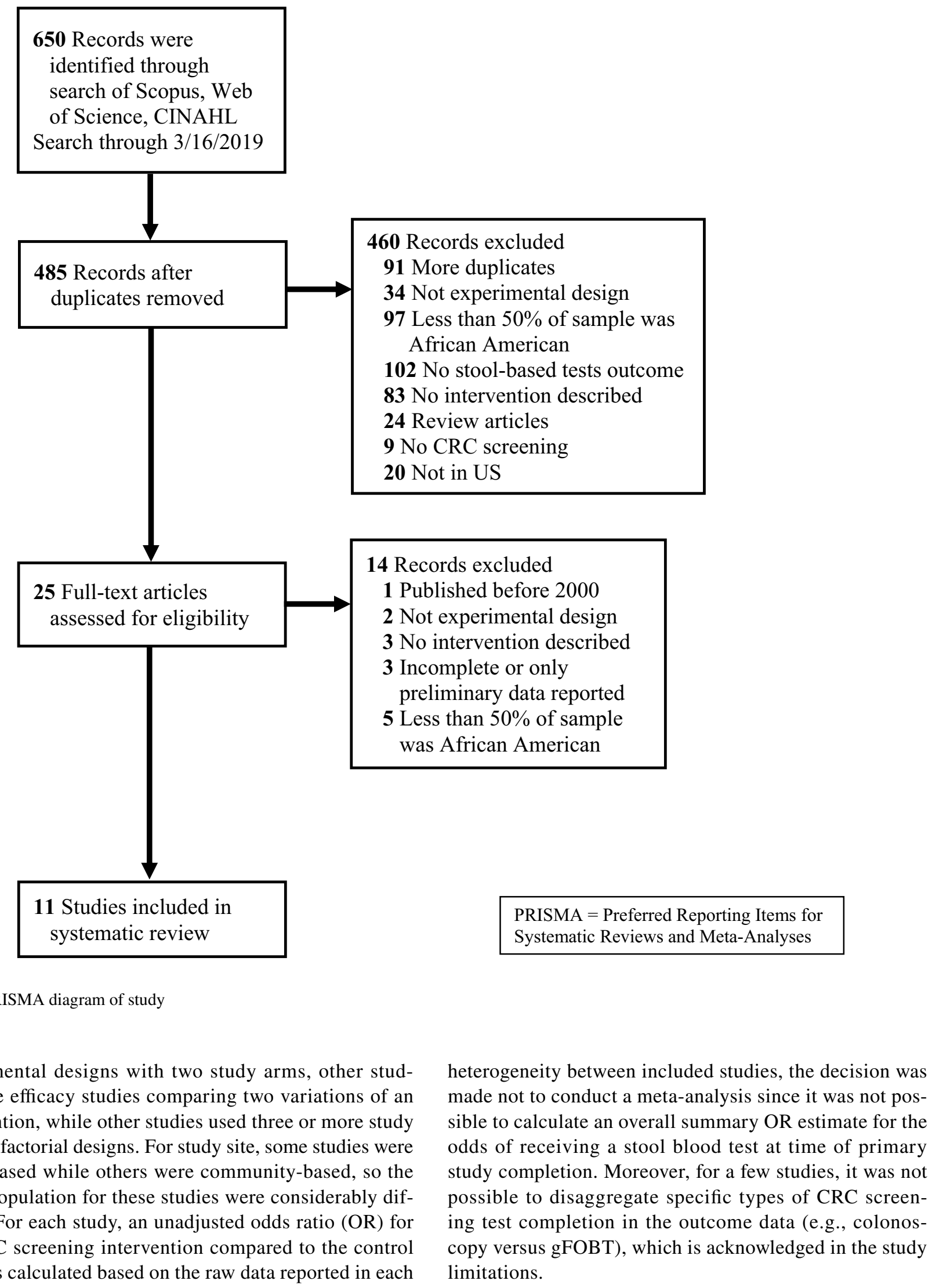

experimental designs with two study arms, other studies were efficacy studies comparing two variations of an intervention, while other studies used three or more study arms or factorial designs. For study site, some studies were clinic-based while others were community-based, so the target population for these studies were considerably different. For each study, an unadjusted odds ratio (OR) for the CRC screening intervention compared to the control arm was calculated based on the raw data reported in each study to determine the effectiveness. Given the substantial heterogeneity between included studies, the decision was made not to conduct a meta-analysis since it was not possible to calculate an overall summary OR estimate for the odds of receiving a stool blood test at time of primary study completion. Moreover, for a few studies, it was not possible to disaggregate specific types of CRC screening test completion in the outcome data (e.g., colonoslimitations. 


\section{Results}

For the 11 identified studies, eight of the studies included African American study participants of greater than $80 \%$ of the total sample (Table 1). Three of the studies included study samples of African Americans ranging between 62 and $70 \%$ [22, 23, 31]. The 11 included studies had greater proportion of African American women participants compared to men (range 59-88\%). Most of the 11 studies included participants in the age range for recommended colorectal cancer screening (i.e., 50 to 75 years). However, of the 11 studies, one study focused on only older participants between 65-75 years [28], and two studies enrolled older individuals up to age 80 years [26] or 94 years [30]. Education level varied among participants in the included studies. Four of the studies reported that $>70 \%$ of participants had completed high school [14, 22-24], whereas four other studies reported $<45 \%[14,22-24,27-29,31]$. The other three included studies did not report on education level $[25,26,30]$.

Included studies varied in study designs (Table 2). Six of the studies were randomized controlled trials with two study arms. Many of these studies were comparing an enhanced intervention in clinical settings, such as using patient navigation or telephone outreach compared to a standard intervention approach using mail-delivered stool blood tests. Other two-arm studies were efficacy studies, for example comparing different combinations of educational materials for FIT completion [14] or comparing variations of a church-based community intervention [27]. Three of the other included studies employed three study arms or a factorial design. The interventions in these studies included community-based approaches (e.g., lay health advisors) [24] and educational approaches in clinics (e.g., pamphlets and videos) $[22,30]$. Two of the included studies conducted interventions in rural areas [22, 24].

The results for the two-arm randomized controlled studies ranged in effectiveness (Table 3). Some studies reported modest improvements. For example, one study reported a $27 \%$ increase in CRC screening from baseline using a telephone outreach strategy [23] and another study reported a $44 \%$ increase in CRC screening from baseline using a video intervention [25]. However, a few studies reported more dramatic increases in CRC screening participation, with one study reporting an $82 \%$ screening adherence postintervention from implementing a tailored print intervention and FIT kit [14]. The five studies using two-arm experimental designs ranged in effectiveness with odds ratios (OR) ranging from 1.1 to 13.0 using interventions such as mailed reminders, patient navigation, and tailored educational materials $[23,25,26,28,29]$. While the study by Goldberg et al. [26] had a large OR (13.0; CI 3.7-46.5), there was a small sample size of only 119 participants. Two studies with large samples which focused on increasing stool blood testing were found to have findings that did not reach statistical significance, such as the study by Friedman et al. [25] with an OR of 1.4 (CI 0.7-2.7) and the study by Horne et al. [28] with an OR of 1.1 (CI 0.7-1.6). The Myers et al. study [29] tested a tailored navigation intervention compared to standard mailed reminders and found significant results with an OR of 1.5 (CI 1.0-2.2) for the FIT screening outcome only.

The results for the three-arm studies also ranged in effectiveness (Table 4). Similar to the two-arm studies, some studies reported modest differences between intervention and control. For example, one study reported a $17 \%$ increase in CRC screening from baseline using a tailored print and video intervention [24]; a second study reported a $30 \%$ increase in CRC screening from baseline using a decision aid intervention [31]; and a third

Table 1 Demographics: percent representation by race, ethnicity, gender

\begin{tabular}{|c|c|c|c|c|c|c|c|c|c|c|}
\hline Study & Black & $\begin{array}{l}\text { Hispanic/ } \\
\text { Latina }\end{array}$ & White & $\begin{array}{l}\text { Asian/Asian } \\
\text { American }\end{array}$ & $\begin{array}{l}\text { Native } \\
\text { American }\end{array}$ & Other & Male & Female & Mean age $^{\mathrm{a}}$ & $\begin{array}{l}\text { High school } \\
\text { completion }\end{array}$ \\
\hline Arnold et al. [22] & 70 & - & 30 & - & - & - & 20 & 80 & - & 71 \\
\hline Basch et al. [23] & 63.2 & - & 16.2 & - & - & 19.7 & 28.9 & 71.1 & - & 89.9 \\
\hline Campbell et al. [24] & 99 & - & - & - & - & - & 26 & 74 & 52 years & 84.1 \\
\hline Christy et al. [14] & 93 & 3 & - & - & - & 7 & 52 & 48 & 56 years & 77 \\
\hline Friedman et al. [25] & 87.5 & 5 & 5 & - & - & 2.5 & 15.6 & 84.4 & 61 years & - \\
\hline Goldberg et al. [26] & 82.4 & 3.3 & 9.2 & - & - & 5.1 & 26 & 74 & - & - \\
\hline Holt et al. [50] & 100 & - & - & - & - & - & 30.2 & 69.8 & 60 years & 9.1 \\
\hline Horne et al. [28] & 100 & - & - & - & - & - & 27.5 & 72.5 & - & 43.5 \\
\hline Myers et al. [29] & 100 & - & - & - & - & - & 31.4 & 68.6 & - & 40.5 \\
\hline Powe et al. [30] & 84 & - & 16 & - & - & - & 12 & 88 & 74 years & - \\
\hline Schroy et al. [31] & 62 & - & 34 & 1 & - & 2 & 41 & 59 & - & 22 \\
\hline
\end{tabular}

${ }^{a}$ When mean age not reported, age categories and percentages were often reported instead, refer to articles for details 


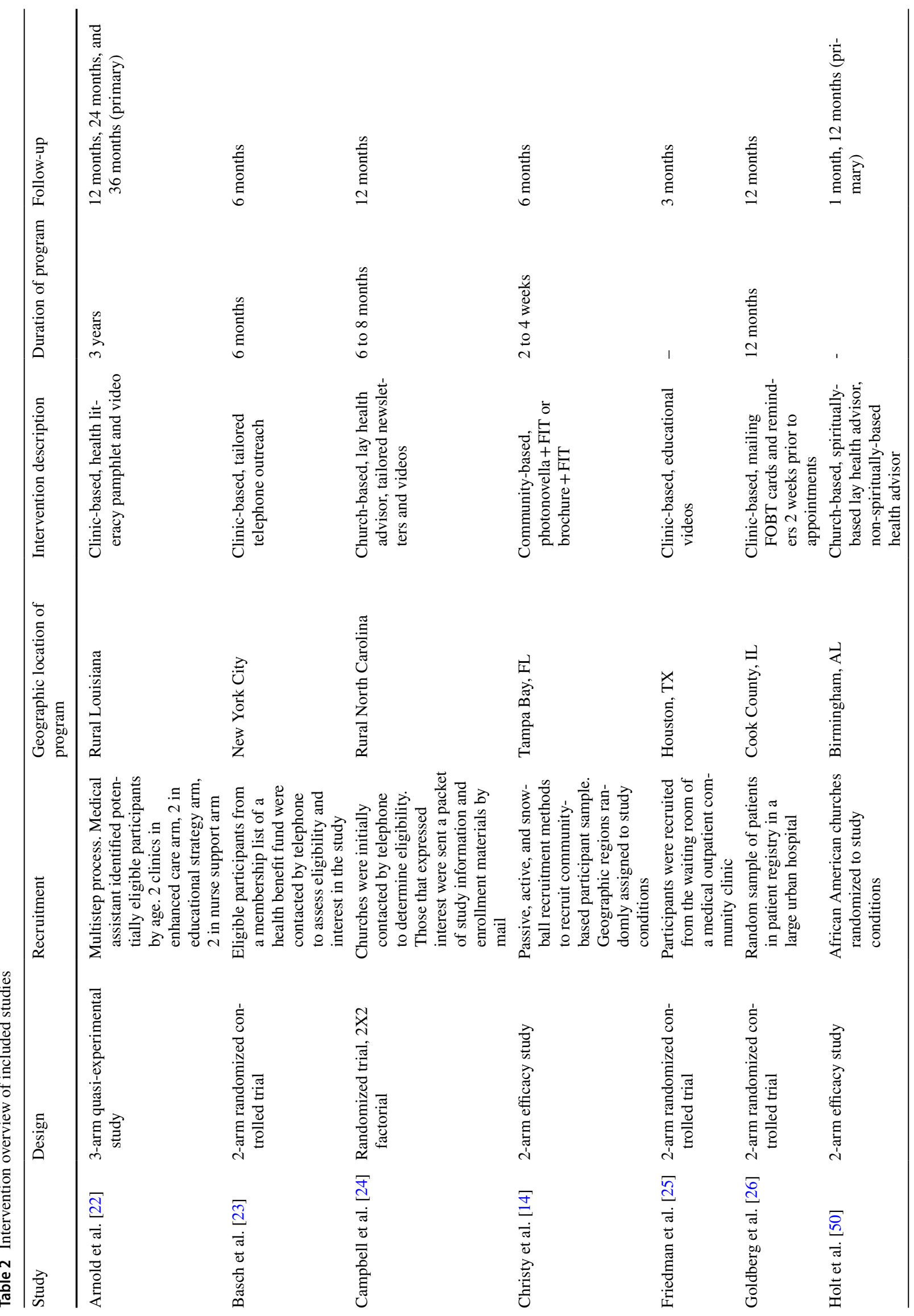




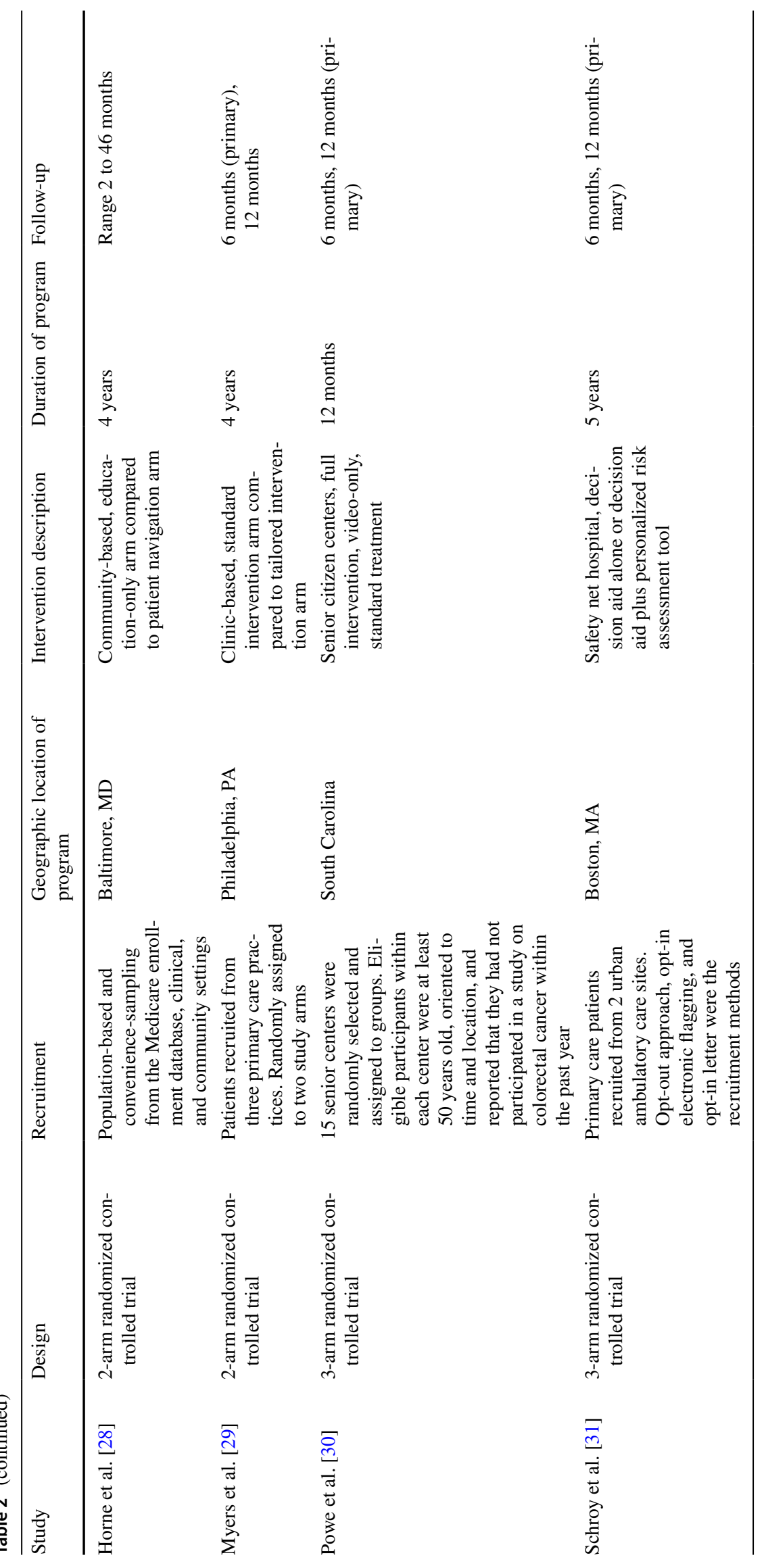


Table 3 Screening effectiveness for stool blood tests of included two-arm studies

\begin{tabular}{|c|c|c|c|c|c|c|c|}
\hline Study & Screening test & $\begin{array}{l}\mathrm{N} \text { (inter- } \\
\text { vention/ } \\
\text { control) }\end{array}$ & $\begin{array}{l}\text { Baseline adher- } \\
\text { ence, } \mathrm{n}(\%) \\
\text { (intervention) }\end{array}$ & $\begin{array}{l}\text { Follow-up } \\
\text { adherence, n (\%) } \\
\text { (intervention) }\end{array}$ & $\begin{array}{l}\text { Baseline } \\
\text { adherence, } \\
\mathrm{n}(\%) \\
\text { (control) }\end{array}$ & $\begin{array}{l}\text { Follow-up } \\
\text { adherence, n (\%) } \\
\text { (control) }\end{array}$ & OR $(95 \% \mathrm{CI})$ \\
\hline $\begin{array}{l}\text { Basch } \\
\text { et al. [23] }\end{array}$ & $\begin{array}{l}\text { FOBT, sig- } \\
\text { moidoscopy, } \\
\text { colonoscopy }\end{array}$ & $226 / 230$ & 0 & $61(27)$ & 0 & $14(6.1)$ & $\begin{array}{l}5.70 \\
(3.08-10.55)\end{array}$ \\
\hline Basch et al. [23] & FOBT only & $226 / 230$ & 0 & $30(13)$ & 0 & $1(0)$ & $\begin{array}{l}39.27(5.30- \\
290.97)\end{array}$ \\
\hline $\begin{array}{l}\text { Christy } \\
\text { et al. [14] }\end{array}$ & FIT & $144 / 186$ & 0 & $118(81.9)$ & 0 & $168(90.3)$ & $0.27(0.15-0.50)$ \\
\hline $\begin{array}{l}\text { Friedman et al. } \\
\text { [25] }\end{array}$ & FOBT & $110 / 50$ & 0 & $48(43.6)$ & 0 & $18(36)$ & $1.38(0.69-2.74)$ \\
\hline $\begin{array}{l}\text { Goldberg et al. } \\
\text { [26] }\end{array}$ & FOBT & $59 / 60$ & 0 & $24(40.7)$ & 0 & $3(5)$ & $13.03(3.65-46.48)$ \\
\hline Holt et al. [50] & FOBT & $152 / 133$ & $15(9.9)$ & $12(7.9)$ & $8(6)$ & $20(15)$ & $0.48(0.23-1.03)$ \\
\hline Horne et al. $[28]^{\mathrm{a}}$ & $\begin{array}{l}\text { FOBT, sig- } \\
\text { moidoscopy, } \\
\text { colonoscopy }\end{array}$ & $578 / 642$ & $476(82.5)$ & $543(94)$ & $527(82.1)$ & $584(91)$ & $1.54(1.00-2.38)$ \\
\hline Horne et al. $[28]^{\mathrm{b}}$ & FOBT only & - & - & - & - & - & $1.09(0.72-1.64)$ \\
\hline Myers et al. [29] ${ }^{c}$ & $\begin{array}{l}\text { FIT, } \\
\text { colonoscopy }\end{array}$ & $384 / 380$ & 0 & $145(38)$ & 0 & $90(23.7)$ & $1.95(1.43-2.68)$ \\
\hline Myers et al. [29] ${ }^{c}$ & FIT only & $384 / 380$ & 0 & $82(21.5)$ & 0 & $58(15.3)$ & $1.51(1.04-2.19)$ \\
\hline
\end{tabular}

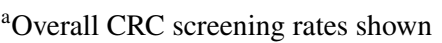

${ }^{\mathrm{b}} \mathrm{OR}$ reported in article, raw numbers not reported

${ }^{\mathrm{c}} 6$ months primary outcome data shown

Table 4 Screening effectiveness for stool blood tests of included three-arm studies

\begin{tabular}{|c|c|c|c|c|c|c|c|}
\hline Study & Screening test & $\begin{array}{l}\mathrm{N} \text { (inter- } \\
\text { vention/ } \\
\text { control) }\end{array}$ & $\begin{array}{l}\text { Baseline Adher- } \\
\text { ence, \% (inter- } \\
\text { vention) }\end{array}$ & $\begin{array}{l}\text { Follow-up } \\
\text { Adherence, \% } \\
\text { (intervention) }\end{array}$ & $\begin{array}{l}\text { Baseline adher- } \\
\text { ence, } \\
\text { (control) }\end{array}$ & $\begin{array}{l}\text { Follow-Up } \\
\text { Adherence, } \\
\% \\
\text { (control) }\end{array}$ & OR $(95 \% C I)$ \\
\hline Arnold et al. $[22]^{\mathrm{a}}$ & FOBT & $90 / 116$ & 0 & $44(48.9)$ & 0 & $55(47.4)$ & $1.06(0.61-1.84)$ \\
\hline $\begin{array}{l}\text { Campbell et al. } \\
{[24]^{\mathrm{b}}}\end{array}$ & FOBT & $76 / 69$ & $15(19.7)$ & $28(36.8)$ & $21(30.4)$ & $15(21.7)$ & $2.1(1.00-4.39)$ \\
\hline Powe et al. $[30]^{\mathrm{c}}$ & FOBT & $54 / 80$ & 0 & $33(61)$ & 0 & $23(29)$ & $3.89(1.88-8.09)$ \\
\hline Schroy et al. $[31]^{\mathrm{d}}$ & $\begin{array}{l}\text { FOBT, sig- } \\
\text { moidoscopy, } \\
\text { colonoscopy, } \\
\text { DCBE, } \\
\text { FOBT + flexible } \\
\text { sigmoidoscopy }\end{array}$ & $269 / 276$ & $35(13)$ & $116(43.1)$ & $36(13)$ & $96(34.8)$ & $1.42(1.01-2.01)$ \\
\hline
\end{tabular}

${ }^{a}$ Enhanced care and health literacy education arms combined, compared to nurse support arm, 36 months outcome data shown

${ }^{\mathrm{b}}$ Tailored print and video arm compared with control arm reported. The tailored print and video arm was more effective compared to the control arm than the lay health advisor arm compared to the control arm, which is not reported here

${ }^{\mathrm{c}}$ Cultural and self-empowerment arm, compared to modified and traditional arms combined, 12 months outcome data shown

${ }^{\mathrm{d} O v e r a l l ~ s c r e e n i n g ~ r a t e s ~ s h o w n ; ~ c o m p a r i s o n ~ b e t w e e n ~ d e c i s i o n ~ a i d ~ v s . ~ c o n t r o l ~ a r m . ~ D C B E, ~ d o u b l e-c o n t r a s t ~ b a r i u m ~ e n e m a ~}$

study reported a $49 \%$ increase in CRC screening from baseline using different variations of a mailed intervention [22]. However, one study reported a more dramatic increase in CRC screening of $61 \%$ screening adherence post-intervention following receipt of a tailored group intervention using video education in senior centers [30]. While several of these studies used either 6-month or 12-month primary outcomes, a few studies examined 
repeat stool blood testing outcomes during a longer time period, such as the study by Arnold et al. which examined third-year stool blood testing outcomes [22].

For nine of the 11 studies included in the review which used random assignment of participation to intervention or control arm, there was relatively low attrition of participants. For the clinical studies, outcomes could be tracked for virtually all participants through electronic patient records. A few studies reported higher research participant attrition between 33 and $42 \%$. The most common limitation reported was the higher number of African American female participants than male in several studies. In addition, a few studies cited CRC screening outcomes based on self-report, which is less reliable than patient chart verification (Table 5).

\section{Discussion}

This systematic review examines summary findings from 11 experimental studies designed to test the effectiveness of interventions to increase colorectal cancer screening, specifically using stool blood CRC screening approaches such as FIT or gFOBT in African American communities. The eleven studies together enrolled a total of 4364 participants (88\% African American). Based on these summary findings which tested effectiveness of clinical and behavioral interventions, a tailored navigation approach either by telephone or in person, might be a potentially effective strategy for increasing CRC screening in African American communities as these interventions tested in two arm studies to control conditions were associated

Table 5 Methodological quality of included studies

\begin{tabular}{|c|c|c|c|}
\hline Study & Allocation methods & Attrition & Other potential limitations \\
\hline Arnold et al. [22] & Quasi-experimental & Low attrition reported (9\%) & $\begin{array}{l}\text { Method of determining FOBT receipt not } \\
\text { reported. Differences between arms in socio- } \\
\text { demographics, and sample was predominately } \\
\text { composed of African American female partici- } \\
\text { pants in FQHCs }\end{array}$ \\
\hline Basch et al. [23] & Random assignment & $\begin{array}{l}\text { Low attrition ( } 7 \% \text { in intervention arm; } 4 \% \text { in } \\
\text { control arm) }\end{array}$ & $\begin{array}{l}\text { All participants had health insurance and a physi- } \\
\text { cian, and stool blood test kits were not provided }\end{array}$ \\
\hline Campbell et al. [24] & Random assignment & Medium attrition reported ( $42 \%)$ & $\begin{array}{l}\text { Method of determining CRC screening was } \\
\text { based on self-report. There was a small sample } \\
\text { size and factorial design limited comparative } \\
\text { analysis }\end{array}$ \\
\hline Christy et al. [14] & Random assignment & Not reported & $\begin{array}{l}\text { Not possible to isolate providing the FIT kit from } \\
\text { print educational materials since both study } \\
\text { arms used educational materials in the efficacy } \\
\text { study }\end{array}$ \\
\hline Friedman et al. [25] & Random assignment & Not reported & $\begin{array}{l}\text { Sample was predominately composed of African } \\
\text { American female participants }\end{array}$ \\
\hline Goldberg et al. [26] & Random assignment & No attrition reported $(0 \%)$ & $\begin{array}{l}\text { Study was completed at one clinical primary care } \\
\text { setting site. Study was completed only in one } \\
\text { single year, so repeat FOBT card return data } \\
\text { were not collected }\end{array}$ \\
\hline Holt et al. [50] & Random assignment & Low attrition reported (10\%) & $\begin{array}{l}\text { Method of determining CRC screening based on } \\
\text { self-report. Participation was not limited based } \\
\text { on not being up-to-date with CRC screening }\end{array}$ \\
\hline Horne et al. [28] & Random assignment & $\begin{array}{l}\text { Low to medium attrition reported ( } 33 \% \text { in inter- } \\
\text { vention arm; } 23 \% \text { in control arm) }\end{array}$ & $\begin{array}{l}\text { Method of determining CRC screening based } \\
\text { on self-report. High percentage of participants } \\
\text { were up-to-date at baseline }\end{array}$ \\
\hline Myers et al. [29] & Random assignment & Low attrition reported $(<1 \%)$ & $\begin{array}{l}\text { The sample was predominately composed of } \\
\text { African American female participants. All par- } \\
\text { ticipants were patients at primary care practices }\end{array}$ \\
\hline Powe et al. [30] & Quasi-experimental & Not reported & $\begin{array}{l}\text { The sample was predominately composed of } \\
\text { African American female participants. There } \\
\text { was a small sample size and 3-arm study design } \\
\text { limited comparative analysis }\end{array}$ \\
\hline Schroy et al. [31] & Random assignment & No attrition reported $(0 \%)$ & $\begin{array}{l}\text { No blinding of providers to one of two interven- } \\
\text { tion arms (decision aid plus personalized risk } \\
\text { assessment or decision aid alone) }\end{array}$ \\
\hline
\end{tabular}


with percentage point differences ranging from 6 to $36 \%$ [23, 25, 26, 29].

The outcomes for the three-arm studies testing variations of interventions in efficacy studies or testing two different variations of an intervention compared to controls, did not report markedly different findings from the two-arm studies. The study by Arnold et al. [22] was unique because it reported 3-year outcomes for stool blood testing, an outcome worth examining because of the recommendation for annual screening. Except for the study by Schroy et al. [31], the studies using experimental designs other than two-arm experimental designs had relatively small sample sizes. The study by Schroy et al. [31] reported that a decision aid improved overall CRC screening rates, but did not report outcomes separately for stool blood testing. The study by Christy et al. [14] was particularly notable for the very high FIT kit return of $87 \%$ of all participants, and the finding that prior screening status did not predict uptake. In this study, African American participants either received a FIT kit plus a CDC standard CRC screening educational brochure or FIT kit plus a tailored photonovella, as well as reminder letters for those not returning the FIT kit within a month-long timeframe, and both approaches were effective.

Two of the included studies, both three-arm studies, were identified as taking place in rural areas [22, 24]. Previous literature has found that the types of screening tests used for colorectal cancer may differ between rural and urban settings [33]. Screening rates by colonoscopy or sigmoidoscopy have increased in both rural and urban populations; however, screening rates via FOBT have decreased in urban populations but increased in rural populations, possibly due to greater access to colonoscopy in urban areas and lack of access to colonoscopy services in rural settings [33]. The results from the two included studies in rural areas reported increases in CRC screening uptake, specifically FOBT screening, which provides further support for the preference for FOBT screening in rural areas.

This systematic review included studies that implemented interventions in clinic or community settings. Our results showed that the two-arm studies that were implemented in clinic-based settings had higher odds ratios than the two-arm studies implemented in community-based settings. Based on these results, implementing CRC screening interventions in clinic-based settings may lead to greater CRC screening uptake among African Americans than community outreach strategies outside of a clinical setting, possibly due to clinical interactions, audit and feedback systems, or other electronic means to remind patients of screening appointments.

Another finding in this systematic review indicated females were more likely to engage in FIT and FOBT, which is consistent with the results of studies examining stool based testing in articles that were eventually excluded after thorough review [34-38]. However, in the included studies, there were larger samples of women than men, which might partially explain these findings, as well as highlight the challenges of recruiting African American men to cancer screening studies. The findings from this group of articles also suggests the promise of culturally tailored interventions to improve CRC screening, such as the use of trusted community venues (e.g., churches, barber and beauty shops) to recruit participants and the implementation of patient navigation approaches to increase trust in providers.

More research is needed to test effective interventions for increasing CRC screening in minority communities and to test whether combined modalities or offering stool blood testing as a frontline strategy increases overall CRC screening rates. Unfortunately, some African American communities have higher levels of uninsured individuals, poor access to healthcare services, lower perceived benefits of CRC screening, lower perceived risk of colorectal cancer, and lower engagement in preventive health behaviors [39, 40]. The previously listed factors have also been cited as barriers for engaging minorities in CRC screening [12, 41]. In light of the economic burden of CRC screening, utilizing FIT and gFOBT can provide a low-cost first-line screening test and be the deciding factor for medically underserved communities to engage in colorectal cancer screening [42]. An examination of the studies in this review identified this frontline screening strategy with FIT or gFOBT can be cost effective. A previous study by Hester et al. [42] indicated stool blood testing presented fewer barriers for completion such as lack of transportation to the facility, bowel preparation, and absence from work, which may impede CRC screening with colonoscopy. When the barriers to CRC screening are removed, there is an opportunity to increase rates of screening among minority and non-minority groups. Consistent with the literature, our findings indicated the feasibility and acceptability of FIT and gFOBT in African American communities as a primary screening strategy (Baker et al. 2014; Davis et al. 2010; Rawl et al. 2008).

This systematic review focused on stool blood testing as one convenient method to increase CRC screening in medically underserved communities. Other studies using experimental designs reported similar findings but were excluded because of smaller African American patient samples [37, $38,43]$. Some identified studies employed other minority samples in their interventions. For example, the experimental study by Muller et al. [44] reported the effectiveness of the low-cost strategy of text messaging for increasing CRC screening among Alaska Native patients. Even though the current systematic review only included studies with a substantial representation of African American study participants, other studies examining diverse populations also reported the need for innovative interventions to increase CRC screening in different community and clinical settings. 


\section{Clinical Implications}

Based on the Healthy People 2020 objectives, the 2020 target for adults between 50 and 75 years to receive CRC screening was $70.5 \%$; however, 2018 data indicated only $65.2 \%$ of adults had completed screening [45]. This systematic review provides some evidence for future strategies to promote CRC screening, especially for increasing the use of FOBT among African Americans. Behavioral interventions may be more efficient if delivered through mail reminders or by using patient navigators. The content of such interventions should include tailored messages. If tailored materials are not available, a standard CRC screening educational brochure may also be effective. For rural African Americans, if primary care settings are not easily reachable, FOBT may be a more accessible choice and preferable method to promote CRC screening behavior. Furthermore, the screening rates achieved by these interventions fall well short of the goal of $80 \%$ screening rate (by 2018 and in every community) proposed by the National Colorectal Cancer Round Table (NCCRT), which includes the American Cancer Society and the Centers for Disease Control and Prevention (CDC) [46].

\section{Strengths and Limitations}

The rigor of the current systematic review lies in the methodology for the article search protocol pertaining to inclusion criteria (e.g., type of study design, peer-reviewed studies in scientific journals, presence of comparison groups) and search strategy. However, some studies may not have been included in the initial search because of the particular search terms used or article indexing procedure that may have excluded an article from the search. The included studies varied in study quality. Seven of the 11 studies included randomization of study participants, and five of the 11 studies were randomized controlled trials. Because of variations in reporting study findings and not stratifying by screening modality, for a few studies it was not possible to isolate the effect of the stool blood testing method. It is recommended that screening outcomes are disaggregated in the reporting of study outcomes. A meta-analysis was not possible for this review because of the heterogeneity in study designs and reported outcomes. Some studies did not report odds ratios so the decision was made to calculate odds ratios for all studies based on the data presented in each article. A systematic review of U.S.-based CRC screening interventions reported that CRC screening interventions which include a combination of screening methods might be most effective; however, most clinic-based interventions might need to provide the array of screening options if they are part of their menu of services [47]. Some clinics, such as federally-qualified health centers (FQHC), might only provide stool blood testing and referral to colonoscopy, so these types of clinics would be more likely to be study sites for a stool blood testing approach only. Future reviews might include all stool blood testing interventions regardless of population served to determine preferences in actual clinical practice settings to test whether they may be differences by geography or racial group.

\section{Conclusion}

The option to choose stool blood testing is part of a comprehensive cancer education approach to increase CRC screening. Our findings align with the Healthy People 2020 objective, which seeks to increase colorectal cancer screening based on current guidelines. Recent guidelines from leading medical and community health organizations (i.e., United States Preventative Task Force, the American Cancer Society, the American Academy of Family Physicians, and Task Force on Community Preventive Services) recommend the use of stool blood testing for colorectal cancer screening, ideally leading to early detection and a reduction in mortality rates $[48,49]$. The low-cost and decreased barriers compared to colonoscopy (e.g., time off work, access to a medical facility, and transportation) might provide an opportunity for some minority populations experiencing CRC disparities to increase participation in screening. However, without sufficient knowledge of these tests and the recommended screening intervals for such screening, minority communities cannot receive the full benefits of CRC cancer prevention. Strategies to increase stool blood testing in African Americans include standard mailed blood stool tests augmented by patient navigation, tailored educational materials, and follow-up calls or mailings to increase trust in the patient-provider relationship. To increase overall CRC screening in African Americans also requires decreasing barriers to access for preventive screenings by increasing insurance coverage and lowering out of pocket healthcare costs.

Funding This article was supported in part by funding from the National Institute on Minority Health and Health Disparities of the National Institutes of Health under Award Number U54 MD007582. The content is solely the responsibility of the authors and does not necessarily represent the official views of the National Institutes of Health. The research was also supported in part by funding from the American Cancer Society, Institutional Research Grant through the Penn State Cancer Institute at Penn State Health Milton S. Hershey Medical Center.

Data Availability Scopus, Web of Science, and CINAHL. 


\section{Compliance with Ethical Standards}

Conflict of interest The authors declare that they have no conflict of interest.

\section{References}

1. DeSantis, C. E., Miller, K. D., Goding Sauer, A., Jemal, A., \& Siegel, R. L. (2019). Cancer statistics for African Americans, 2019. CA: A Cancer Journal for Clinicians, 69(3), 211-233. https ://doi.org/10.3322/caac.21555.

2. Siegel, R. L., Miller, K. D., \& Jemal, A. (2019). Cancer statistics, 2019. CA: A Cancer Journal for Clinicians, 69(1), 7-34. https:// doi.org/10.3322/caac.21551.

3. Carethers, J. M. (2018). Clinical and genetic factors to inform reducing colorectal cancer disparitites in African Americans. Frontiers in Oncology, 8, 531. https://doi.org/10.3389/ fonc.2018.00531.

4. Coughlin, S. S., Blumenthal, D. S., Seay, S. J., \& Smith, S. A. (2016). Toward the elimination of colorectal cancer disparities among African Americans. Journal of Racial and Ethnic Health Disparities, 3(4), 555-564. https://doi.org/10.1007/s4061 5-015-0174-z.

5. U. S. Preventive Services Task Force, Bibbins-Domingo, K., Grossman, D. C., et al. (2016). Screening for colorectal cancer: US preventive services task force recommendation statement. JAMA, 315(23), 2564-2575. https://doi.org/10.1001/jama.2016.5989.

6. Issaka, R. B., Rachocki, C., Huynh, M. P., Chen, E., \& Somsouk, M. (2020). Standardized workflows improve colonoscopy followup after abnormal fecal immunochemical tests in a safety-net system. Digestive Diseases and Sciences. https://doi.org/10.1007/ s10620-020-06228-z.

7. Fedewa, S. A., Siegel, R. L., Goding Sauer, A., Bandi, P., \& Jemal, A. (2019). Colorectal cancer screening patterns after the American Cancer Society's recommendation to initiate screening at age 45 years. Cancer. https://doi.org/10.1002/cncr.32662.

8. Rex, D. K., Boland, C. R., Dominitz, J. A., et al. (2017). Colorectal cancer screening: Recommendations for physicians and patients from the U.S. Multi-Society Task Force on Colorectal Cancer. American Journal of Gastroenterology, 112(7), 10161030. https://doi.org/10.1038/ajg.2017.174.

9. Rex, D. K., Johnson, D. A., Anderson, J. C., et al. (2009). American College of Gastroenterology guidelines for colorectal cancer screening 2009 [corrected]. American Journal of Gastroenterology, 104(3), 739-750. https://doi.org/10.1038/ajg.2009.104.

10. Harden, E., Moore, A., \& Melvin, C. (2011). Exploring perceptions of colorectal cancer and fecal immunochemical testing among African Americans in a North Carolina community. Preventing Chronic Disease, 8(6), A134.

11. Gupta, S., Sussman, D. A., Doubeni, C. A., et al. (2014). Challenges and possible solutions to colorectal cancer screening for the underserved. Journal of the National Cancer Institute. https ://doi.org/10.1093/jnci/dju032.

12. Bromley, E. G., May, F. P., Federer, L., Spiegel, B. M., \& van Oijen, M. G. (2015). Explaining persistent under-use of colonoscopic cancer screening in African Americans: A systematic review. Preventive Medicine, 71, 40-48. https://doi.org/10.1016/j. ypmed.2014.11.022.

13. Bailey, J. R., Aggarwal, A., \& Imperiale, T. F. (2016). Colorectal cancer screening: Stool DNA and other noninvasive modalities. Gut and Liver, 10(2), 204-211. https://doi.org/10.5009/gnl15420.

14. Christy, S. M., Davis, S. N., Williams, K. R., et al. (2016). A community-based trial of educational interventions with fecal immunochemical tests for colorectal cancer screening uptake among blacks in community settings. Cancer, 122(21), 32883296. https://doi.org/10.1002/cncr.30207.

15. Chen, L. A., Santos, S., Jandorf, L., et al. (2008). A program to enhance completion of screening colonoscopy among urban minorities. Clinical Gastroenterology and Hepatology, 6(4), 443-450. https://doi.org/10.1016/j.cgh.2007.12.009.

16. Percac-Lima, S., Grant, R. W., Green, A. R., et al. (2009). A culturally tailored navigator program for colorectal cancer screening in a community health center: A randomized, controlled trial. Journal of General Internal Medicine, 24(2), 211-217. https:// doi.org/10.1007/s11606-008-0864-x.

17. Luque, J. S., Wallace, K., Blankenship, B. F., et al. (2018). Formative research on knowledge and preferences for stool-based tests compared to colonoscopy: What patients and providers think. Journal of Community Health. https://doi.org/10.1007/s1090 0-018-0525-x.

18. Singal, A. G., Gupta, S., Tiro, J. A., et al. (2016). Outreach invitations for FIT and colonoscopy improve colorectal cancer screening rates: A randomized controlled trial in a safety-net health system. Cancer, 122(3), 456-463. https://doi.org/10.1002/cncr.29770

19. Tiro, J. A., Kamineni, A., Levin, T. R., et al. (2014). The colorectal cancer screening process in community settings: A conceptual model for the population-based research optimizing screening through personalized regimens consortium. Cancer Epidemiology, Biomarkers \& Prevention: A Publication of the American Association for Cancer Research, Cosponsored by the American Society of Preventive Oncology., 23(7), 1147-1158. https://doi. org/10.1158/1055-9965.EPI-13-1217.

20. Brown, T., Lee, J. Y., Park, J., et al. (2015). Colorectal cancer screening at community health centers: A survey of clinicians' attitudes, practices, and perceived barriers. Preventive Medicine Reports, 2, 886-891. https://doi.org/10.1016/j.pmedr.2015.09.003.

21. Xirasagar, S., Li, Y. J., Burch, J. B., Daguise, V. G., Hurley, T. G., \& Hebert, J. R. (2014). Reducing colorectal cancer incidence and disparities: Performance and outcomes of a screening colonoscopy program in South Carolina. Advances in Public Health. https://doi.org/10.1155/2014/787282.

22. Arnold, C. L., Rademaker, A., Wolf, M. S., Liu, D., Hancock, J., \& Davis, T. C. (2016). Third annual fecal occult blood testing in community health clinics. American Journal of Health Behavior, 40(3), 302-309. https://doi.org/10.5993/AJHB.40.3.2.

23. Basch, C. E., Wolf, R. L., Brouse, C. H., et al. (2006). Telephone outreach to increase colorectal cancer screening in an urban minority population. American Journal of Public Health, 96(12), 2246-2253. https://doi.org/10.2105/ajph.2005.067223.

24. Campbell, M. K., James, A., Hudson, M. A., et al. (2004). Improving multiple behaviors for colorectal cancer prevention among African American church members. Health Psychology, 23(5), 492-502. https://doi.org/10.1037/0278-6133.23.5.492.

25. Friedman, L. C., Everett, T. E., Peterson, L., Ogbonnaya, K. I., \& Mendizabal, V. (2001). Compliance with fecal occult blood test screening among low-income medical outpatients: A randomized controlled trial using a videotaped intervention. Journal of Cancer Education, 16(2), 85-88.

26. Goldberg, D., Schiff, G. D., McNutt, R., Furumoto-Dawson, A., Hammerman, M., \& Hoffman, A. (2004). Mailings timed to patients' appointments: A controlled trial of fecal occult blood test cards. American Journal of Preventive Medicine, 26(5), 431-435. https://doi.org/10.1016/j.amepre.2004.02.009.

27. Holt, C. L., Litaker, M. S., Scarinci, I. C., et al. (2013). Spiritually based intervention to increase colorectal cancer screening among African Americans: Screening and theory-based outcomes from a randomized trial. Health Education and Behavior, 40(4), 458-468. https://doi.org/10.1177/1090198112459651. 
28. Horne, H. N., Phelan-Emrick, D. F., Pollack, C. E., et al. (2015). Effect of patient navigation on colorectal cancer screening in a community-based randomized controlled trial of urban African American adults. Cancer Causes and Control, 26(2), 239-246. https://doi.org/10.1007/s10552-014-0505-0.

29. Myers, R. E., Sifri, R., Daskalakis, C., et al. (2014). Increasing colon cancer screening in primary care among African Americans. JNCI: Journal of the National Cancer Institute. https://doi. org/10.1093/jnci/dju344.

30. Powe, B. D., Ntekop, E., \& Barron, M. (2004). An intervention study to increase colorectal cancer knowledge and screening among community elders. Public Health Nursing, 21(5), 435-442. https://doi.org/10.1111/j.0737-1209.2004.21507.x.

31. Schroy, P. C., Emmons, K. M., Peters, E., et al. (2012). Aidassisted decision making and colorectal cancer screening: A randomized controlled trial. American Journal of Preventive Medicine, 43(6), 573-583. https://doi.org/10.1016/j.amepre.2012.08.018.

32. Luque, J. S., Logan, A., Soulen, G., et al. (2019). Systematic review of mammography screening educational interventions for hispanic women in the United States. Journal of Cancer Education: The Official Journal of the American Association for Cancer Education, 34(3), 412-422. https://doi.org/10.1007/s1318 7-018-1321-0.

33. Cole, A. M., Jackson, J. E., \& Doescher, M. (2012). Urban-rural disparities in colorectal cancer screening: Cross-sectional analysis of 1998-2005 data from the Centers for Disease Control's Behavioral Risk Factor Surveillance Study. Cancer Medicine, 1(3), 350-356. https://doi.org/10.1002/cam4.40.

34. Davis, T. C., Arnold, C. L., Rademaker, A. W., et al. (2012). FOBT completion in FQHCs: Impact of physician recommendation, FOBT information, or receipt of the FOBT kit. Journal of Rural Health, 28(3), 306-311. https://doi.org/10.111 1/j.1748-0361.2011.00402.x.

35. Lawsin, C., DuHamel, K., Weiss, A., Rakowski, W., \& Jandorf, L. (2007). Colorectal cancer screening among low-income African Americans in East Harlem: A theoretical approach to understanding barriers and promoters to screening. Journal of Urban Health, 84(1), 32-44. https://doi.org/10.1007/s11524-006-9126-6.

36. Martin, R. L., Tully, M., Kos, A., et al. (2017). Increasing colorectal cancer screening at an urban FQHC Using iFOBT and patient navigation. Health Promotion Practice, 18(5), 741-750. https:// doi.org/10.1177/1524839917705127.

37. Myers, R. E., Sifri, R., Hyslop, T., et al. (2007). A randomized controlled trial of the impact of targeted and tailored interventions on colorectal cancer screening. Cancer, 110(9), 2083-2091. https ://doi.org/10.1002/cncr.23022.

38. Rawl, S. M., Champion, V. L., Scott, L. L., et al. (2008). A randomized trial of two print interventions to increase colon cancer screening among first-degree relatives. Patient Education and Counseling, 71(2), 215-227. https://doi.org/10.1016/j. pec.2008.01.013.

39. Buchanan, D., Gubrium, A., Scott, L., \& Douglas, H., Jr. (2018). The cascade of social determinants in producing chronic disease in low-income African-American men. The International Journal of Qualitative Studies on Health and Well-Being, 13(1), 1549920. https://doi.org/10.1080/17482631.2018.1549920.
40. Rogers, C. R., \& Goodson, P. (2014). Male role norms, knowledge, attitudes, and perceptions of colorectal cancer screening among young adult African American men. Front Public Health, 2, 252. https://doi.org/10.3389/fpubh.2014.00252.

41. Williams, R. M., Wilkerson, T., \& Holt, C. L. (2018). The role of perceived benefits and barriers in colorectal cancer screening in intervention trials among African Americans. Health Education Research, 33(3), 205-217. https://doi.org/10.1093/her/cyy013.

42. Hester, C. M., Born, W. K., Yeh, H. W., et al. (2015). Decisional stage distribution for colorectal cancer screening among diverse, low-income study participants. Health Education Research, 30(3), 400-411. https://doi.org/10.1093/her/cyv006.

43. Greiner, K. A., Daley, C. M., Epp, A., et al. (2014). Implementation intentions and colorectal screening: A randomized trial in safety-net clinics. American Journal of Preventive Medicine, 47(6), 703-714. https://doi.org/10.1016/j.amepre.2014.08.005.

44. Muller, C. J., Robinson, R. F., Smith, J. J., et al. (2017). Text message reminders increased colorectal cancer screening in a randomized trial with Alaska Native and American Indian people. Cancer, 123(8), 1382-1389. https://doi.org/10.1002/cncr.30499.

45. Helitzer, D. L., Sussman, A. L., Hoffman, R. M., Getrich, C. M., Warner, T. D., \& Rhyne, R. L. (2014). Along the way to developing a theory of the program: A re-examination of the conceptual framework as an organizing strategy. Evaluation and Program Planning, 45, 157-163. https://doi.org/10.1016/j.evalprogpl an.2014.04.005.

46. Wender, R. C., Doroshenk, M., Brooks, D., Hotz, J., \& Smith, R. A. (2018). Creating and implementing a national public health campaign: The American Cancer Society's and National Colorectal Cancer Roundtable's $80 \%$ by 2018 initiative. American Journal of Gastroenterology, 113(12), 1739-1741. https://doi. org/10.1038/s41395-018-0384-1.

47. Young, B. R., Gwede, C. K., Thomas, B., et al. (2019). A systematic review of U.S.-based colorectal cancer screening uptake intervention systematic reviews: Available evidence and lessons learned for research and practice. Front Public Health, 7, 145. https://doi.org/10.3389/fpubh.2019.00145.

48. Task Force on Community Preventive Services. (2008). Recommendations for client- and provider-directed interventions to increase breast, cervical, and colorectal cancer screening. American Journal of Preventive Medicine, 35(1 Suppl), S21-S25. https ://doi.org/10.1016/j.amepre.2008.04.004.

49. Wilkins, T., McMechan, D., \& Talukder, A. (2018). Colorectal cancer screening and prevention. American Family Physician, 97(10), 658-665.

50. Holt, C. L., Scarinci, I. C., Debnam, K., et al. (2012). Spiritually based intervention to increase colorectal cancer awareness among african americans: Intermediate outcomes from a randomized trial. Journal of Health Communication, 17(9), 1028-1049. https ://doi.org/10.1080/10810730.2012.665418.

Publisher's Note Springer Nature remains neutral with regard to jurisdictional claims in published maps and institutional affiliations. 